$\mathrm{V}, \mathrm{K} \mathrm{K} 659.4$

ББК 60.842

DOI 10.22394/1682-2358-2017-4-111-118

O.I. Molchanova, Candidate of Sciences (Pedagogies), Docent of the International Relations, Media Studies, Political Science and History Department, Saint-Petersburg State University of Economics

\section{THE CONCEPT AND SUBJECTS \\ OF THE SYSTEM TO ENSURE CONTROL OVER CONVERGENT MEDIA FORMATION PROCESSES}

Changes in the contemporary media sphere related to the development of a unique phenomenon of media convergence are analyzed. The concept and elements of the system to ensure control over processes of formation of convergent mass media that influence each other, determining the vector direction of further development are considered.

Key words and word-combinations: media convergence, managing formation processes, convergent media.
О.И. Молчанова, кандидат педагогических наук, дочент кафедри международнихх отношений, медиалогии, политологи и истории Санкт-Петербургского государственного экономического университета (email: moi.2012@bk.ru)

\section{ПОНЯТИЕ И СУБЬЕКТЫ СИСТЕМЫ ОБЕСПЕЧЕНИЯ УПРАВАЕНИЯ ПРОЦЕССАМИ ФОРМИРОВАНИЯ КОНВЕРГЕНТНЫХ MAССМЕАИА}

\footnotetext{
Аннотация. Анализируются изменения в современной медиасфере, связанные с развитием уникального явления медиаконвергентности. Рассматриваются понятие и субъекты системы обеспечения управления процессами формирования конвергентных массмедиа, которые взаимодействуют друг с другом, определяя векторную направленность дальнейшего развития.

Ключевые слова и словосочетания: медиаконвергентность, управление процессами формирования, конвергентные массмедиа.
}

C руются, причем как на глобальном, так и на мокамьном уровне. Формируются массмедиа конвергентного типа с совершенно новыми качественными характеристиками. К начаму 2017 г. в мире не осталось СМИ, редакция которого в той ими иной степени не подверглась процессам медиаконвергенции. Бомьшинство сайтов преАстав яют качественную аудиовизуальную информацию, все 
они обладают интерактивностью, позволяя аудитории принимать участие в усовершенствовании собственного контента.

За последние 15-20 кет средства массовой информации и их способы поАачи новостей претерпели колоссальные изменения, связанные прежде всего с развитием технологий и дигитализаџией - переводом информации в цифровую форму. Если раньше источниками информации были печатная пресса, радио и телевидение, то сегодня к ним добавились мобильные и интернетресурсы. Более того, именно они становятся, а где-то уже стали основными поставщиками новостного контента. Безусловно, Аанную ситуацию можно считать новым этапом развития медиа. Именно онцайн-СМИ позволяют «собрать» разные виды подачи информации, а также Аругие опции в рамках оАной платформы.

Американские исследователи Eugenia Siapera и Andreas Veglis отмечают: «ГАядя на теорию эволюџии, наряду с историей интернет-журнацистики, мы можем утверждать, что некоторые виды СМИ могут исчезнуть, в то время как Аругие адаптируются к окружающей среде. Вымирание может проложить путь к появцению новых видов, в то время как адаптация может привести к интересным и, возможно, более надежным формам журналистики» [1] . Авторы выделяют три главных аспекта эволющии в медиа. Первым аспектом является то, что печатная пресса передает своим «потомкам», то есть онлайнизданиям, такие свои основные черты, как сообщение фактов, представление информационного анализа, комментариев и мнений. Кроме того, сами печатные издания и традиционные СМИ аАаптируются к новым условиям и приходят в Интернет.

Второй аспект эволюџии в медиа - генезис нового вида журнацистики, который имеет свои собственные характеристики и органично вписывается в новую окружающую среду. ЗАесь речь идет именно о новых меАиа, чьи принципы подачи информации отличаются от тех, которые использоваци траАиционные СМИ.

Мутация стала третьим аспектом эволюции. «Журналистика мутировала во что-то новое, Аругое, которое может открыть новые горизонты. Мутации могут возникать случайно и в случайном порядке. ОАнако они могут быть приписаны специфическим изменениям в окружающей среде. В связи с интернет-журналистикой мы можем наблюдать, по крайней мере, Ава таких серьезных изменения: в экономике интернет-журналистики и в нормах ее производства» [1]. Авумя основными формами мутации авторы называют журналистику в социальных сетях и открытых ресурсах.

ПослеАний этап эволюционного развития меАиаконвергентности имеет специфические характеристики. Помимо появления новых СМИ, стоит отметить такое явление, как блогосфера, которая за последние годы превратилась в полноценную новостную площадку. Сегодня блоги стали популярным альтернативными источниками информаџии, иногАа именно они создают информационный повод.

Характерно, что новостной агрегатор Yandex предлагает не только полборку самых актуальных новостей по результатам анализа интернет-СМИ, но 
и по блогам. Вместе с тем блоги постепенно интегрируются и в медиаплатформы. Так, на сайте телеканала, журнала или газеты нередко можно увидеть авторские блоги журналистов, работающих в данном медиа, посреАством которых они осуществляют взаимодействие с аудиторией. С этой же целью происходит проникновение интернет-СМИ в сощиальные сети. Практически у каждого медиа на данный момент существует своя страница в социальных сетях. Вместе с тем социальные сети, как и блоги, могут выступать площадкой Аля размешения собственного новостного контента и создавать информационный повоА. Стандартной практикой также стало цитирование сообщений из Twitter известных Аюдей, в частности, политиков о том или ином событии. На телеканале «Аождњ» в рамках новостей, выходящих в эфир каждый час, на постоянной основе происходит обзор Facebook и Twitter.

Таким образом, очевидно, что обществу необходимо приспосабливаться к новым условиям. Это означает, что в рамках государства необходимо сформумировать концепцию развития, которая учитывала бы грядущие изменения в информационно-коммуникационной сфере, причем не только технического плана. На первое место выходят вопросы социального и соџиально-технологического характера, в их числе проблемы образования (необходимы специалисты для новой сферы деятельности), проблемы, связанные с реорганизацией такого социального института, как журналистика. При этом следует иметь в виду разнообразие существующих медиа с различными организационными структурами, отличающимися экономиками, способами коммуникации, цецевыми аудитории и т.А. Рассмотрим данные вопросы подробнее.

О6 изменении характера современной журналистики пишут многие исследователи, отмечая всеобъемлющий характер этих трансформаций: «Аля современной научной парадигмы опредемяющим становится синергетический подхоА, в контексте которого журналистика может рассматриваться как диссипативная, открытая, нелинейная, динамическая, дискретная система» [2, с. 265].

МежАисџиплинарный подход в синергетическом эффекте имеет основопомагающее значение, особенно продуктивен он в гуманитарных, социальных науках, к которым относится в той или иной мере и теория журналистики. Синергия в развитии современных медиа приводит к следующим результатам: 1) основная функция, организующая деятельность современного СМИ, коммерческая, она определяет целевую структуру редакции, при этом другие функции (идеологическая, просветительская, образовательная) сохраняются, но занимают последующие посме коммерческой функщии места; 2) темы и проблемы, затрагиваемые журналистами, свободны и разнообразны, так как не регулируются каким-то особым регламентом; 3) жанровая система, имеющая четкую структуру, момается и трансформируется, появмяются новые жанровые формы, пограничные жанровые образования; 4) язык современных медиа в результате синергетического эффекта становится более свободным от языковых норм, функциональные стили смешиваются, появляются языковые новообразования. Е.А. Зверева отмечает пятый итог синергетического воздействия: профессиональные критерии в журналистике размываются, возникает Аискуссия необязательности специального образования [2, с. 271] . 
Все чаще в научной митературе при определении современного состояния журналистики употребляется слово «журнализм». Отметим, что журнацизм преАполагает философскую точку зрения на общепринятое понятие журнамистики. Не следует путать понятия «журнализм» и «журналистика», они не идентичны.

«Журнацизм» объемней, вкмючает в свои границы саму профессию журнамиста, составные части информационного пространства [3, с. 657]. Его следует рассматривать как специфическую массовую информаџионную деятельность, связанную «с поиском и передачей актуальной сощиальной информации в ритмизированной, Аискретной форме массовой, вероятностной, рассредоточенной, анонимной аудитории и выступающую тем самым в качестве информаџионного массового коммуникаторства» [4, с. 7]. В этом определении отмечены новые характеристики как самой деятельности, так и формы ее подачи. Автор, выявцяя кардинальные изменения в журналистской профессионацьной Аеятельности, предлагает рассматривать журнализм «на всех уровнях информаџионной организации или информационного поля: от социоприродных (метаинформационных), планетарно-цивилизационных (мегаинформационных) к социальным в рамках определенного общества, страны (макроинформаџионным) и далее - в конкретных более мелких мокальностях и общностях (мезо-, мимлиинформационных) вплоть до конкретных жкурналистских текстов, воспринимаемых мичностью (микро- и мини-информационных). Аанная исходная посылка Аает возможность рассматривать журнализм как социоприродный, цивилизационный, социономический и профессиональный креативный феномен. При этом все уровни феноменологизации нужАаются в анализе не только структурном, но и динамическом, т.е. в осмыслении генезиса и функционирования данных систем во времени, что ведет к рассмотрению журнализма как динамического феномена» [5, с. 28].

Аругой аспект синергетического подхода связан с тем фактом, что российский меАиабизнес пока мало развит, и с экономической точки зрения это объясняет ряд возникающих проблем: отсутствие современной отечественной медиаиндустрии, наличие иностранного капитала, ведущего за собой политические последствия. В результате кризисное состояние ведет к непрозрачности ведения бизнеса, авторитарным методам управмения и монопомизации в информаџионной сфере. «Практически все причины объясняются одним - среди руководителей массмедиа очень мало подготовленных на современном уровне спещиацистов: компетентных, явцяющихся носителями синергетических знаний о СМИ как Ауалистической системе, работающей и как общественный институт, и как субъект экономических отношений» $[6$, c. 351].

Преобразование медийного рынка обусловлено рядом характеристик:

- мономедийная среда традиционных СМИ перестает быть актуальной, формируется мультимедийная среда;

- наблюдается замена кмассификаџионного названия медиа: из СМИ (среАства массовой информации) они трансформируются в СМК (среАства массовой коммуникации); 
- возникает новая форма коммуникации - интерактивность;

- происходит универсализация профессиональных навыков журналистов;

- формируется новый вид журналистики - народной (гражданской);

- усиливается конкуренция медийного бизнеса;

- возникает диверсификация рекламного рынка;

- цифровые технологии изменяют параболу распространения информационного продукта [7, с. 287].

В свою очередь, сближение различных медиа, появление общих для разных каналов содержательных продуктов ведет к рождению новых интегрированных жанров $[8$, с. 79]. Интеграции подвергаются как журналистские, так и рекламные, и PR-тексты. Сращение текстов, по мнению некоторых исследователей, может привести к непредсказуемым последствиям, что отразится на мировоззрении и поведении массовой аудитории. ОАно дело, когАа человек знает, что его информирует рекмама, и Аругое, когда он обрашается к источнику, доверяя свое сознание авторитетному СМИ. Таким образом, «жанровая гетерогенность в массовой коммуникаџии, с одной стороны, свидетельствует о естественной гибкости и подвижности граниџ текстов, но, с Аругой, актуацизирует профессионально-этические и нормативные проблемы, регламентирующие пределы жанровых свобод» [9, с. 38].

Среди новых жанров трансформирующейся журналистики, предполагающей тексты в режиме онлайн, выделяют следующие: онлайн-конференџию, онлайн-репортаж, твиттер-репортаж, онлайн-дневник, журналистский блог. С учетом возможностей мультимедийности можно констатировать появление нового жанра «мультимедийная история», в основе которой межит мультимедийная информаџия (фото, видео, аудио, инфографика). В рамках мультимедийной истории размичают такие жанровые формы, как аудиослайдшоу, интерактивный видеомост, интерактивная видеоколонка, мультимедийное ток-шоу и Аругие. Следует отметить, что устоявшейся классификаџии пока нет, так как процесс формирования и становления новых жанровых образований находится в начале своего пути.

Трансформация происходит и на уровне требований к профессиональным качествам журналиста. Востребованы универсалы, способные работать в современной конвергируюшейся среде. Аیя нового глобального журнализма нет границ. Журнализм вплетается во все виды информации, все больше влияя на общественное мнение. Появмяются такие понятия, как «мультимедиажурна-

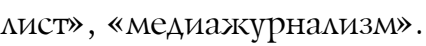

Трансформируется восприятие информаџии в сфере медиа, оно становится многоуровневым, многослойным и многомерным. В связи с этим появцяется понятие «multitasking generation» («многозадачное поколение») [10, с. 289]. Ситуация, которую немьзя бымо представить еще десять мет назад, становится типичной: индивид может одновременно слушать радио, работать с разными интернет-ресурсами, отвечать на звонки телефона, вести переговоры по скайпу. Подобный стиль существования порождает новый тип мышления, то есть «реальная клиповость, многомерность и совмещаемость разных информаџионных рядов - это реальность мультимедийного журнализма. Свойство муль- 
тимедийности, или коммажности, становится одним из основных признаков журнацизма» [2, с. 266] .

Сеть, благодаря которой происходит векторное преобразование медиасферы, обладающая такими свойствами, как мультимедийность, многоканаць-

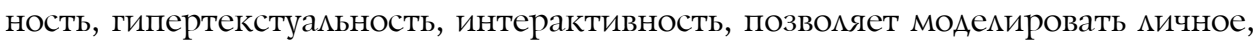
индивидуальное, субъективное медиапространство, где медиа становятся незаменимым партнером пользователя. «Впервые появились предпосылки и возможности функщионирования массмедиа не как системы массового информирования и манипулирования (которая существовала с момента создания СМК), но как системы и среды неиерархического коммуницирования медиа и аудитории» [11].

Медиа становятся неотьемлемой частью жизни современного человека, их влияние стремительно возрастает. В образовательной системе в ближайшие годы могут произойти значительные перемены с учетом того, что специалист Аолжен знать современные технические устройства, профессионацьно пользоваться ими, а также уметь критически осмысливать происходящие события. Рынком востребованы профессионалы, имеющие навыки поиска, обработки и трансляции информации, анализа медиатекстов. Грядут социально-экономические изменения как по всему миру, так и в России, связанные с новейшим информационным прорывом, что требует пересмотра традиционных подхоАов, методов и технологий в обучении современных специалистов.

Медиа можно рассматривать как средство освоения человеком окружающего мира по самым разным направлениям - интемлектуальному, нравственному, соџиальному, творческому, психологическому и иным. Цели их использования тоже могут быть разные: удовцетворение информационных потребностей, получение образовательных услуг, развлечение, коммуникация с комлегами, Арузьями, решение бытовых проблем. Результаты воздействия

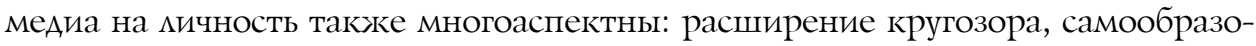
вание и самовоспитание, самоутверждение и самоопределение, социализация и Аругое.

Функции современных медиа рассматриваются многими учеными. Анализ существующих классификаций (Я.Н. Засурского, Е.П. Прохорова, А.В. Федорова, А.Н. Федотовой, И.А. Фомичевой, И. Хмары) дает основания дия разделения их на соответствующие группы:

- информаџионная: доставка информации в соответствии с запросом потребителя;

- анацитическая: предоставцение возможности выбора потребителю на основе анацитических материалов;

- образовательная (просветительская): массмедиа способствуют расширению кругозора потребителя;

- нравственно-воспитательная: массмедиа способствуют (правда, не всегда и не все) формированию общественных ценностей и морально-нравственных установок;

- социально-управленческая (регуцятивная): массмедиа вцияют на обественное мнение и поведение мюдей; 
- рекреационная: направлена на обеспечение Аосуга, снятие напряжкения после рабочего Аня;

- эстетическая: Амя удовлетворения эстетических потребностей аудитории.

К перечисленному следует добавить, на наш взгляА, социализирующую функщию, которая выходит на одно из первых мест в связи с виртуацизацией жизни молодой аудитории, Аля которой важно утвержАаться и реализовываться в данном пространстве.

Итак, целями системы обеспечения процессов управцения формированием конвергентных массмедиа являются, во-первых, активизация процессов интеграции сообщества на основе принципа общечеловеческих ценностей, морали и нравственности; во-вторых, недопущение деградации населения изза негативного воздействия некоторых информационных ресурсов; в-третьих, формирование преемственного профессионального образования, обеспечивающего информационный рынок квалифицированными кадрами, способными работать в условиях медиаконвергентности.

Аля достижения џелей используются разцичные средства.

Технические средстъа: современные ИТ и медиапиатформы, цифровые гаджеты, позволяющие оперативно, регуцярно, на принщипах массовости и доступности работать с современными информационными потоками.

Организационныле средстьа. На базе традиционной редакции возникает новая организационная структура, конвергентная редакция, способная решать задачи, стоящие перед редакционным комлективом в соответствии с информационными потребностями современной аудитории.

Информационные средстьа. Современная система СМИ: печатные, электронные массмедиа, информационные агентства.

Финансовие средства. Они необходимы дия переоборудования редакционного комплекса в процессе формирования конвергентной редакции.

Прабобие средства. Подразумевается внесение изменений в существующие законы и издание подзаконных актов, отражающих истинное положение в сфере массмедиа.

Кадрољие средстъа. Имеется в виду необходимость в новых кадрах, способных обеспечивать функционирование конвергентных массмедиа, а также повышение квалификации «старых» кадров с целью их адаптации к новым условиям.

Интеллектуальные средства. Привлечение к леятельности профессионалов высокого класса, научных кадров, опытных практиков, управленцев, способных решать актуацьные социальные задачи в условиях трансформации современной медиасферы.

В «компетенцию» медиаконвергентности прямо или косвенно входят практически все цели, задачи и средства обеспечения процессов управления формированием конвергентных массмедиа. Государство в проџессах управления выступает определяющим субъектом, это макроуровень. Индивид в современной медиасфере является определяющим субъектом как на макроуровне, так и на микроуровне одновременно.

Субъекты и система обеспечения процессов управления формированием 
конвергентных массмедиа взаимодействуют Аруг с Аругом, оказывая значительное влияние, определяя векторную направленность Аальнейшего развития. Подобный характер взаимоотношений субъектов и системы конвергентных массмедиа влияет на социальные процессы и явления, возникающие в ходе формирования меАиаконвергентности, что обусловцивает соџиологический подход к исследованию формирования, управления и функщионирования конвергентных массмедиа.

\section{Библиографический список}

1. Siapera E., Veglis A. The Handbook of Global Online Journalism / Editor(s). URL: http:// onlinelibrary.wiley.com/book/10.1002/9781118313978page3.

2. Зверева E.A. Журналистика эпохи постмодерна: векторы исследования // Социальноэкономические явления и процессы. 2011. № 10 (032). С. 265-272.

3. Епанчинцев B.B. Социально-философский феномен журнализма // Молодой ученый. 2014. № 7. C. 657-659.

4. Свитич Л.Г. Феномен журнализма. М., 2000.

5. Свитич Л.Г. Журналистика в контексте современных научных парадигм: учебное пособие. М., 2012.

6. Основы медиабизнеса / под ред. Е.Л. Вартановой. М., 2009.

7. Уразова С.Л. Конвергенция как фактор жизнеспособности масс-медиа в цифровой среде // Вестник Нижегородского университета им. Н.И. Лобачевского. 2011. № 5 (1). С. 287-293.

8. Бакулев Г.П. Конвергенция медиа и журналистика. М., 2002.

9. Современный медиатекст: учебное пособие / отв. ред. Н.А. Кузьмина. Омск, 2011.

10. Балмаева С.Д. «Многозадачное поколение», конвергенция, новые роли журналистов // Неожиданная современность: меняющиеся реалии XXI века. Мир - Россия - Урал: материалы XIII Всероссийской научно-практической конференции Гуманитарного университета: доклады: в 2 т. Екатеринбург, 2010. Т. 2.

11. Шилина М.Г. Медиакоммуникация: тенденции трансформации. Новые парадигмы исследований массовых коммуникаций // Медиаскоп. 2009. Вып. 3. URL: http://www. mediascope.ru/ 